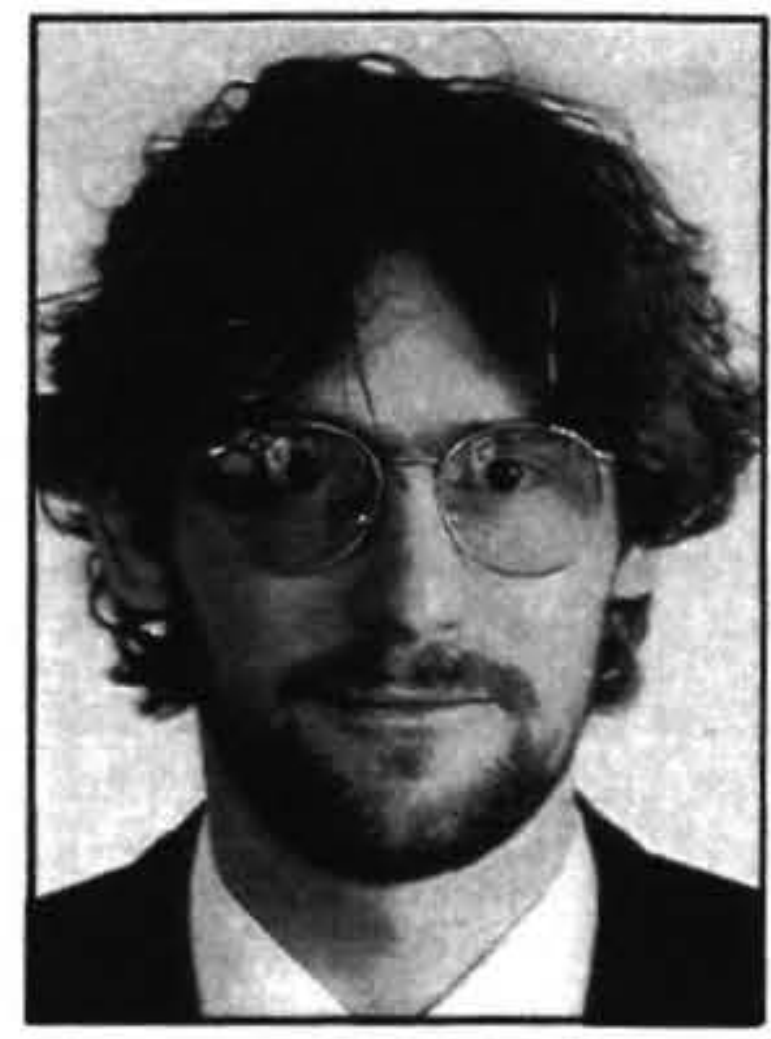

\title{
TRENDS IN MAORI AND NON- MAORI LABOUR FORCE PARTICIPATION, INCOMES AND RESTRUCTURING, 1981 TO 1991
}

\author{
Ben Amey \\ Population Studies Centre \\ University of Waikato
}

\begin{abstract}
The aim of this paper is to determine the relative impact of economic restructuring on Maori during the 1980s and early 1990s. The data come from special tabulations compiled from Census data. A combination of income classes and medians are used as measures to identify trends by ethnicity, family type, and labour force status. In particular, Maori and NonMaori labour force participation rates are compared with income distribution trends to determine relationships between income levels and labour force participation. The degree of Maori income inequality increased during hte 1980s both relative to 1981 and to Non-Maori families in 1991.
\end{abstract}

This paper represents a work in progress aimed at assessing the impact of employment restructuring of the 1980s on the Maori Family, over the period from 1981 to 1991. The effects of the period of restructuring in the 1980s has created much debate within the field of income distribution, especially with regards to poverty. This paper is directed at assessing the income inequality of Maori families compared to Non-Maori families.

\section{Conceptualising Poverty}

There are two central concepts of poverty acknowledged by researchers (RCSS, Stephens et al) making it necessary to distinguish between absolute (primary) poverty and relative (secondary) poverty (Stephens, 1992).

Absolute poverty is known as subsistence, people barely having enough basic elements with which to live; their basic needs being food, water and shelter . Absolute poverty is of more relevance to a less developed country such as India and relative, or secondary poverty, is more appropriate to a country such as New Zealand whose history of welfare provision has been well established in the context of the Welfare State.

Secondary poverty as defined by the Economic Council of Canada refers to those who are disadvantaged enough that it adversely affects their ability to belong to and participate in the community (Royal Commission on Social Security, 1972: 65,104). In 1972 the Royal Commission on Social Security (RCSS) adopted the Canadian definition of relative poverty when they stated that

"the aims of the system should be:

(i) First, to enable everyone to sustain life and health; (ii) Second, to ensure, within limitations which may be imposed by physical or other disabilities, that everyone is able to enjoy a standard of living much like that of the rest of the community, and thus is able to feel a sense of participation in and belonging to the community;

(iii) Third, where income maintenance alone is insufficient (for example, for a physically disabled person), to improve by other means, and as far as possible, the quality life available. (Royal Commission on Social Security, 1972: 65,104)

Part (i) refers directly to the elimination of absolute poverty, and part (ii) refers to elimination of secondary poverty. Secondary poverty is linked with low socio-economic conditions, the identification of criteria is required to define this broad category due to the subjective nature of poverty as defined in part (ii) by the Royal Commission on Social Security.

The criteria required to define secondary poverty involve deciding at what level of income families lose the ability to participate within the community, and at what level this inability to participate represents poverty. These are social judgements that cannot represent an actual poverty but rather a socially determined unacceptable level. It is therefore more helpful to consider the concept of income inequality.

Income equality is easy to measure, as this is when "every income receiver earns exactly the same sum in income" (Bryant, 1979:29). However, while the converse can be said of income inequality, it is hard to measure as it can take innumerable forms. In market based economies income inequality is regarded as necessary because "it is believed that persons with skills would not use their abilities fully 
enough unless there were differences between the pay packets of skilled and unskilled workers (Bryant, 1979:29). The ideal for governments is a "minimum practicable inequality" or a point which is subjectively determined to be an adequate level of inequality. ${ }^{\prime}$

\section{New poverty}

Since the mid 1970 s poverty has returned to the political agenda of many countries as a central point of reference for judging societies systems of distributing work and welfare. During the 1980s social researchers, political leaders, and the mass media have pointed to signs that new forms of poverty are developing, or that new groups of the population are falling into poverty. According to these claims, high levels of long term unemployment, economic restructuring and recent socio-demographic trends are exposing new weaknesses in the post-war systems of welfare provisions and social security; new lines of social division and new patterns of dependency are developing; and financial support for the new poor is imposing an increasing burden on public administration (Balsen, et al, 1984).

The new poor, particularly those affected by the continuing high rates of unemployment, are said to be characterised by the suddenness of their fall from comfort and security into poverty; and by their inability to cope with misfortune, as witness their debts and their lack of skill in using the systems of public relief, supposedly a trait of the traditional poor.

Certainly in New Zealand's case the dramatic rise in people using private foodbanks has been well documented in recent years, coinciding with large-scale redundancies as the state sector downsized it's workforce. The scale of unemployment is relatively new to New Zealand, considering the near full employment rates of the 1950s and 1960s. The fear expressed by many working in this field is that the loss of full employment is denying major sections of the population the opportunity to secure their livelihood through work; and simultaneously leaving large numbers of the population dependent upon public relief. 'New poverty' is new within recent experience and as something which, rather than being a carry-over from the past, is generated by the process of economic and industrial development itself.

Blackburn and Bloom (1987) studied the income distribution of total family income, across families, and income distribution across individuals. Income inequality in their article is measured two ways, firstly, with a Gini coefficient, and secondly, by classifying each income unit (family or individual) into one of five categories according to their relationship to the median level of income. Their classes are as follows.

Lower Class (LC) $\quad=<60 \%$ of the median income Lower Middle Class (LMC) $=>60 \%<100 \%$ of the median income Middle Class (MC) $\quad=>100 \%<160 \%$ of the median income Upper Middle Class (UMC) $=>160 \%<225 \%$ of the median income Upper Class (UC) $\quad=<25 \%$ of the median income

(Blackburn and Bloom, 1987: 579)
The Gini coefficient, shows whether the share of income is spread equally across the population, and the class based method, out-lined above, is used to pinpoint the location of changes in the income distribution, "a function that is not provided by a one dimensional inequality measure like the Gini coefficient" (Blackburn and Bloom, 1987, 575). The class based measure also has another advantage over the Gini coefficient, it is not biased by the changes, or lack of changes, to the top coded bracket, as the top income class is below the highest income bracket.

The lower class (LC) and lower middle class (LMC) income groups represent families below the median income, and together are equal to half of the total share of family income and likewise with the other three income classes for the upper half of the income distribution. The proportion of families in each income classes depict the structure of the income distribution. The greater the number of families in the Lower Class (LC) the less equal the lower half of the distribution. For the other half of the distribution, the greater the number of families in the Upper Class (UC) and to a lesser extent the Upper Middle Class (UMC) the greater the inequalities, especially if there is a concentration of families at opposite ends of the distribution, in the LC and the UC.

The advantages of this method are that it is relatively simple and intuitive, yet effective at illustrating changes to income inequality. The Gini coefficient denotes the overall changes to income inequality and the class measure elucidates the change in income inequality by pin-pointing the reasons behind the change by indicating the areas of change. The Blackburn and Bloom measure described above can easily be applied to the New Zealand context.

The empirical research of Blackburn and Bloom have been expanded to incorporate a further dimension, by linking the lowest income class bracket boundary (LC) to New Zealand poverty line research. To determine the setting of the upper boundary of the Lower Class (LC) income range a suitable representation of poverty was needed and here the 1994 research by Richard Sawrey and Charles Waldegrave was used. $^{2}$

Sawrey and Waldegrave conducted a consensual based (subjective) poverty measure in and around the Wellington and Hutt region. The reasons they give for using a consensual based technique are that "focus groups provide a basis for different household types, cultural communities and economic status to develop an interactive view as to the income level required to achieve the defined standard of living" (Stephens, 1995, 2). The standard of living is defined as "minimum participation, or that the family can take part in church, school and local activities, but not visit the pub or cinema" (Stephens, 1995, 2). The advantages of the technique are that the "participants bring their own expertise, knowledge and experience to the determination of living standards" (Stephens, 1995, 2), but how this knowledge is managed could determine the 'accuracy' of the findings. The results provide a benchmark standard of living which is both absolute; representing a standard of living which households should not fall below; and is relative to economic 
conditions within New Zealand (Stephens, Waldegrave and Frater, 1995, 88).

Sawrey and Waldegrave used six focus groups divided by ethnicity (Maori,Pakeha and Samoan, all low income groups), and also by single parent, low wage earner and pakeha middle income earners (Waldegrave and Sawrey, 1994). Sawrey and Waldegrave provided for two categories in their results, the first was for a Two Adult Three Child family and the second for a One Adult Two Child family. To achieve a dollar amount each focus group devised a household weekly operating budget which did not allow for any savings to be made other than superannuation, but had provisions for activities/recreation and exceptional emergencies which included money for family and church. The results were then calculated as a percentage of the 1993 Mean and Median income for Sole Parent Families, Two Parent Families and Couple Only Families.

To adequately reflect the varying needs of families according to family size it is important that the number of dependent children is considered. The problem when studying Maori income by family type and by number of dependent children is that the number of responses in each table is greatly reduced which can reduce the accuracy of mean and median calculations. To incorporate the effect of dependent children and retain a larger population, the average number of children was calculated, by family type, for each census and was applied to the focus group results. The focus group results with only 'Two Adult Three Children' and 'One Adult Two Children' categories, did not provide enough family sizes for an adequate interpolation so the Whiteford equivalence scales were used to adjust the categories to match the average family size for both the 'Two parent' and 'Sole parent' family types. The focus group results now matched their respective average family size and were then calculated as a percentage of the 1993 mean and median income of each family type.

The definition of the Lower Class (LC) income bracket of the Blackburn and Bloom method of 60 percent of the median was replaced by the focus group result percentage. This is the case for Two parent families at 52 percent of the median and 44 percent of the mean, and for Couple Only families at 48 percent of the median and 38 percent of the mean. Due to the high relationship between Sole parent family poverty and the mean and median of Sole parent families, 134 and 96 per cent respectively, the lower three classes (LC, LMC and MC) for the median and the bottom half for the mean (LC and LMC), are taken to represent the population in poverty.

\section{The results}

In 1981 the distribution for Maori Two Parent Families was clustered in the lower end of the income distribution (see Figures 1-3) with roughly sixty five percent of the Maori population below the median for Two Parent families. Many Maori Two Parent Families were in the Lower Middle Class but 21 percent of Maori families were in the Lower Class (LC) in 1981 and 1986, but the number of poor (LC) had reached 25 percent by 1991 . Yet the Maori distribution became more equal in 1986 due to decreases in the Lower Middle Class (LMC), but as this rose again in 1991 the position of Maori had reverted to levels of inequality similar in structure to that of 1981 .

Figures 4 through 6 show that the Non-Maori population had higher percentages of their population in the higher income classes (UMC and UC) in 1981 than for Maori. Poverty was half the level of Maori in the Lower Class (LC) at only 10 percent. But poverty increased for the Non-Maori population throughout the period to reach 13 percent in 1991. The UMC share grew from 1981 to 1986 as the UC shrank, but the UC grew from 1986 to 1991 . These changes meant Non-Maori Two Parent families became more unequal compared with their 1981 position, as greater percentages became LC and UMC at the different ends of the income distribution. When compared with Maori, the NonMaori distribution was still represented in higher percentages in the upper classes (UMC and UC) and at lower percentages in the LC, but not to the same extent as in 1981.

Maori Couple Only Families in 1981 had relatively high levels of poverty, or families in the Lower Class (LC) of the income distribution- see Figures 7 through 9. The Maori share of the LC in the period from 1981 to 1986 saw poverty fall from just under 20 percent to under 10 percent, but by 1991 this had risen to almost 20 percent again. The percentage in the LMC rose from 1981 to 1986 but dropped between 1986 and 1991, so that the overall level of Maori below the median remained roughly at the 1986 level and lower than 1981 , despite the rise in the percentage of the LC. In 1986 Maori families were more equal than the Non-Maori distribution, having lower levels in the LC, UC and due to the increases to the MC and UMC share of the distribution. By 1991 this had reversed and the MC level had fallen while the UC and the UMC grew. The Maori Couple Only family distribution in 1991 had greater inequality than 1986 but was almost identical to the distribution in 1981, except for the higher percentages in the MC in 1981 and the higher level of LMC in 1991, making the 1981 distribution the most equal of the period.

Figures 10 to 12 show that the distribution for Non-Maori was roughly comparable to Maori in 1981, except the NonMaori distribution had higher levels in the UC while Maori had higher levels in the MC. The Non-Maori share of poverty (LC) decreased from 1981 to 1986 by about five percent, with a corresponding increase in the levels of the LMC and the MC. There was a reversal of this trend from 1986 to 1991 with a drop in poverty and an increase in the LMC, but there was also an increase in the UC. Over the period 1981 to 1991 poverty levels fell and the LMC grew, but also the MC fell and the UMC and the UC grew resulting in little change to inequality, but rather a re-emphasis of the inequality with higher levels at the top of the distribution and also less at the lower end of the distribution.

The income distribution for Maori Male Sole Parent families in 1981 was very unequal (see Figures 13 to 15), with 65 percent in the upper income classes of UMC and UC, yet also 
Figure 1 Maori Couple Only Family Median, 1981

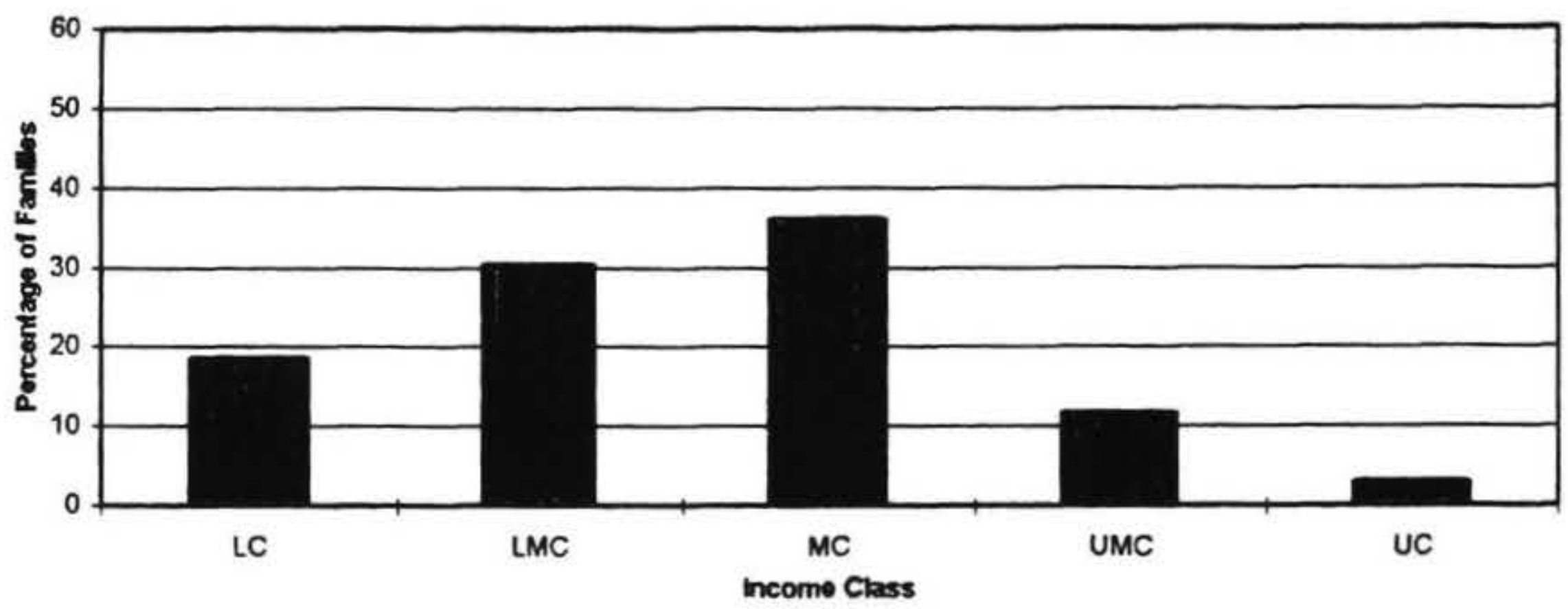

Figure 2 Maorl Couple Only Family Median, 1986

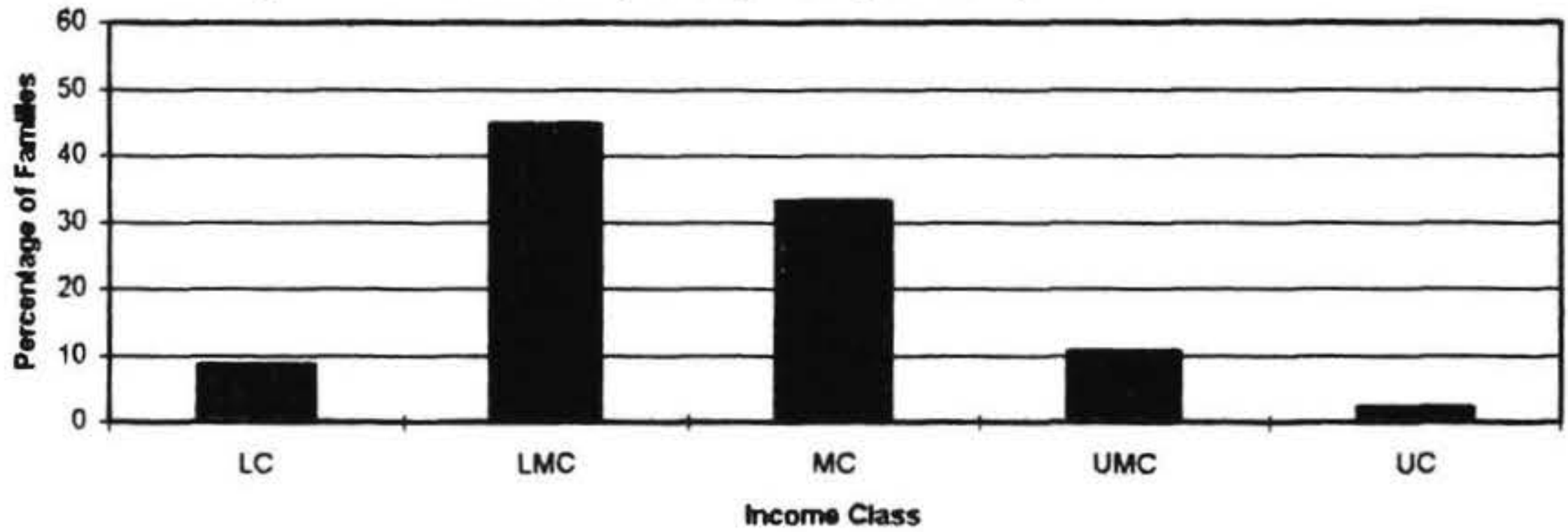

Figure 3 Maori Couple Only Family Median, 1991

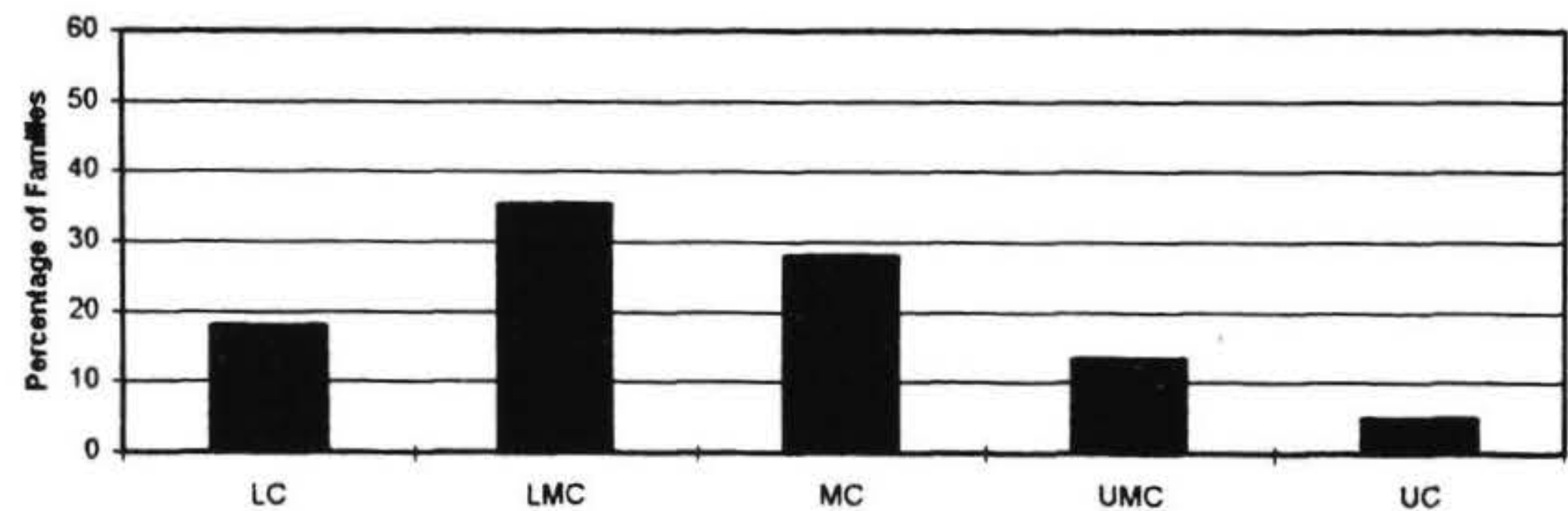

income Class

Figure 4 Non-Maori Couple Only Family Median, 1981

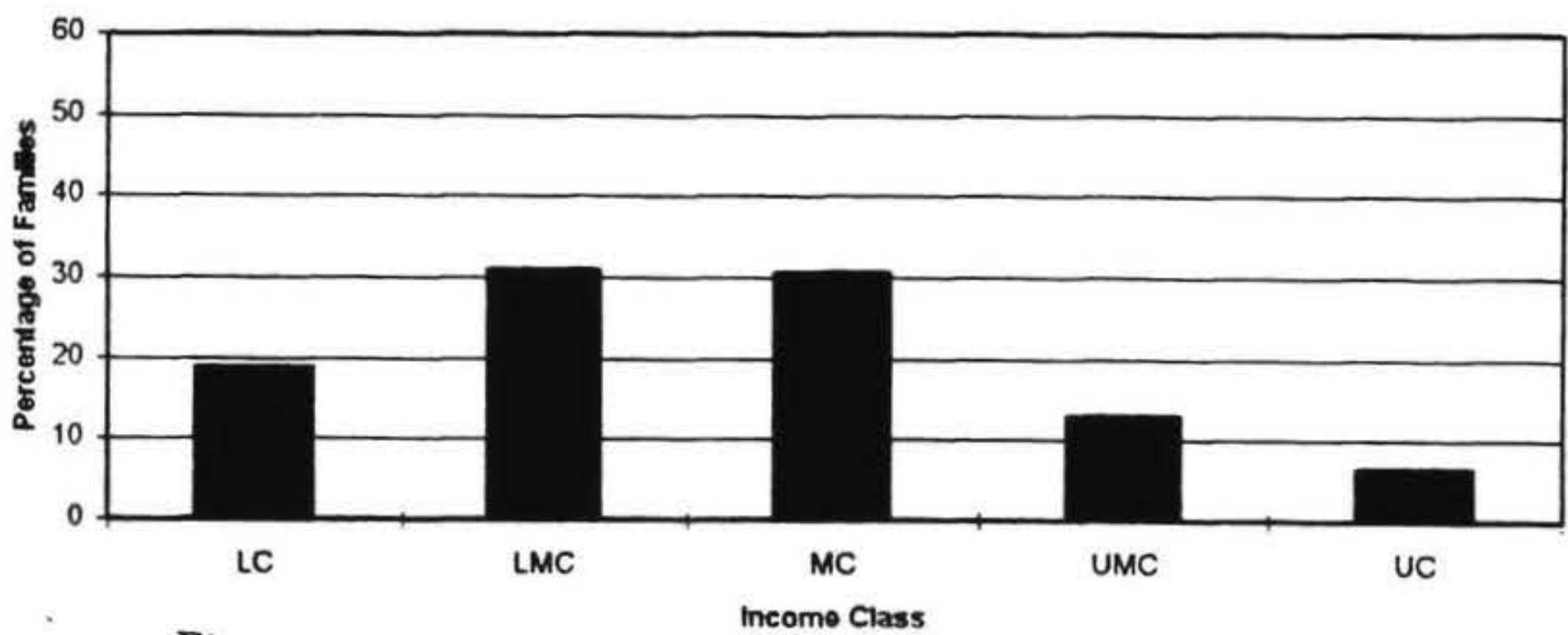

Figure 5 Non-Maorl Couple Only Family Median, 1986

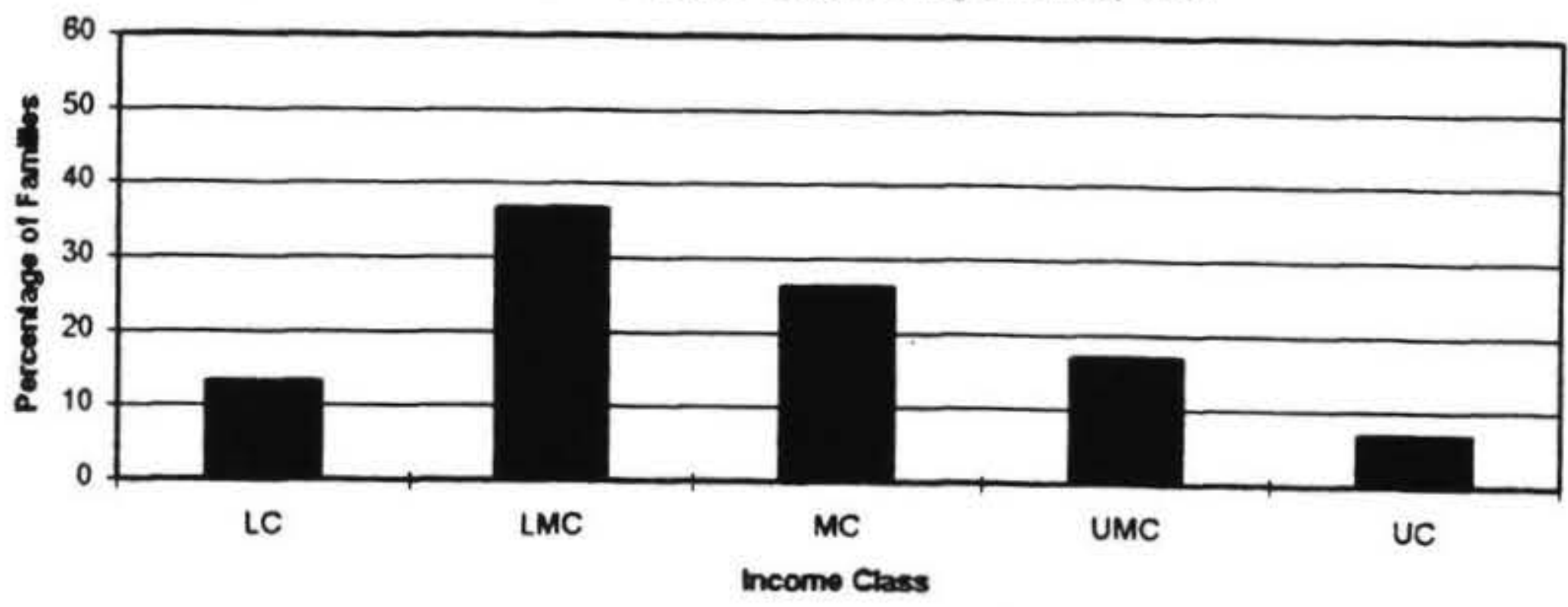


Figure 6 Non-Maori Couple Only Family Median, 1991

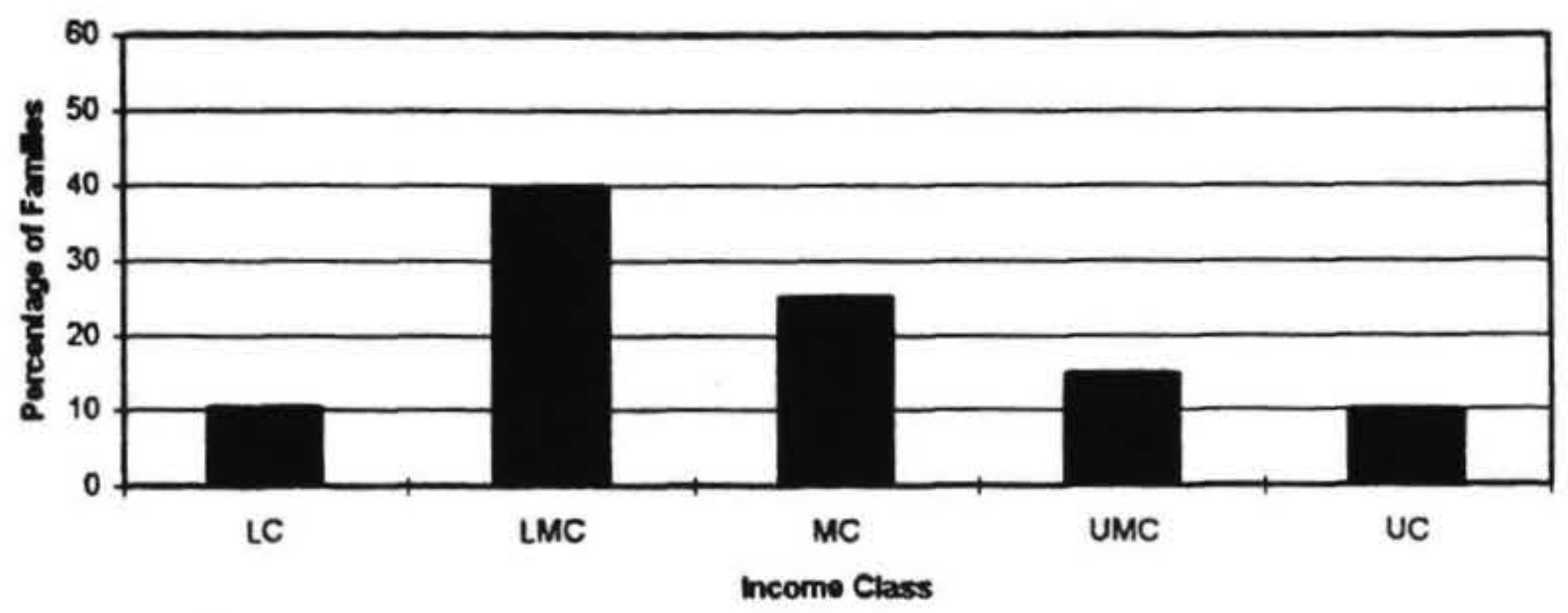

Figure 7 Maori Two Parent Family Median, 1981

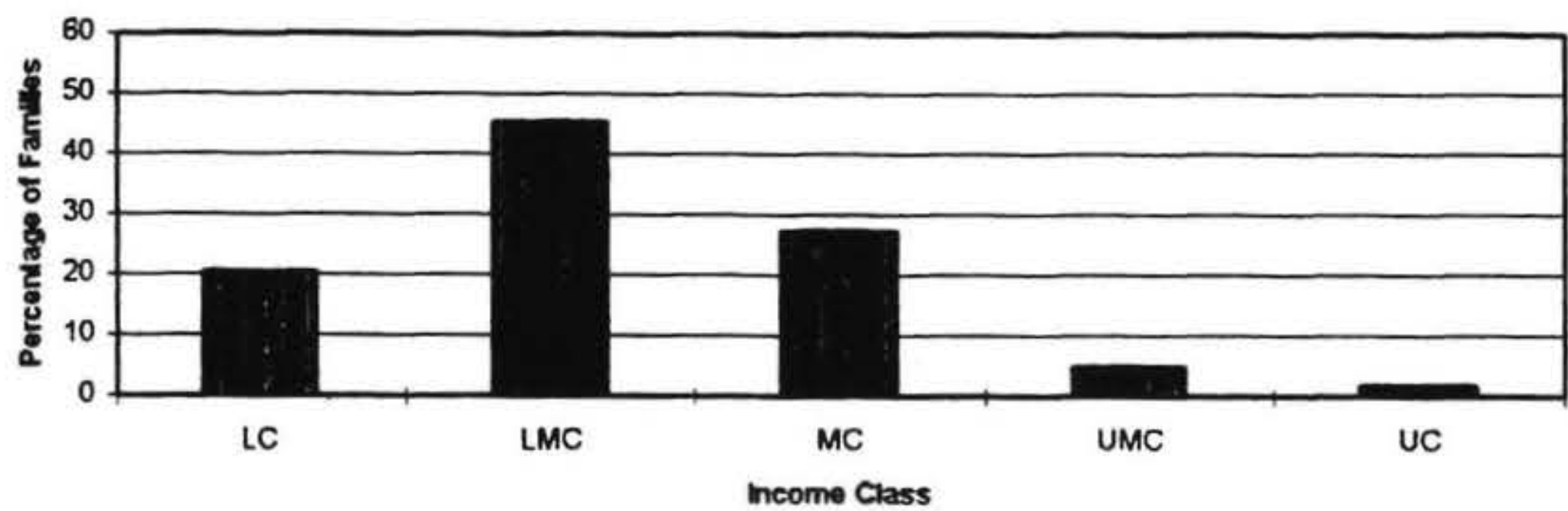

Figure 8 Maori Two Parent Family Median, 1986

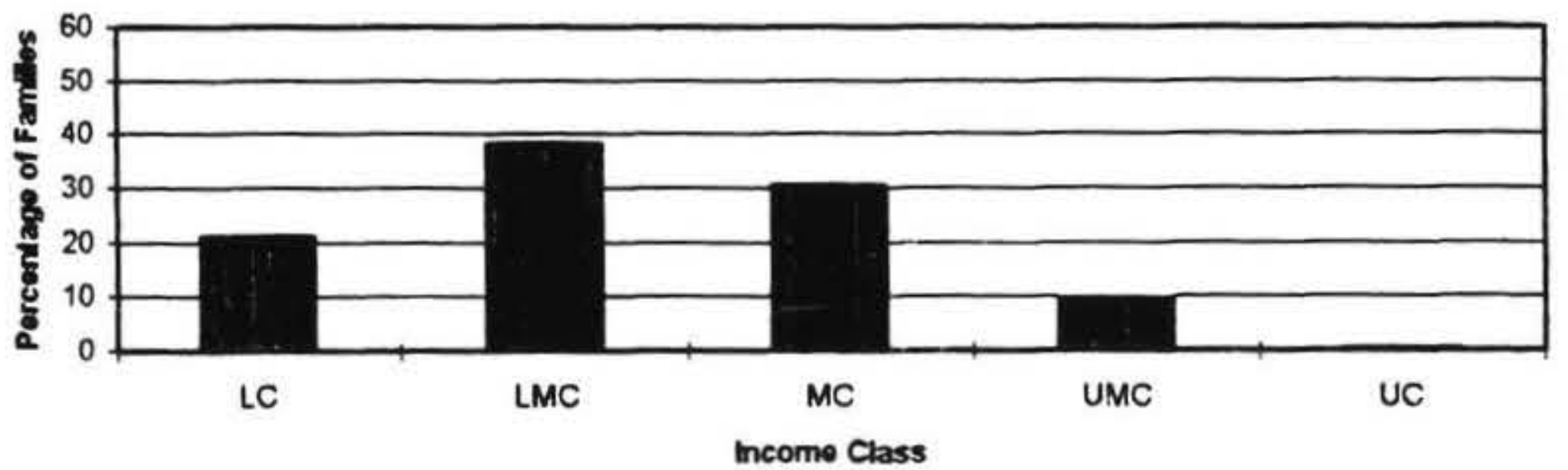

Figure 9 Maori Two Parent Family Median, 1991

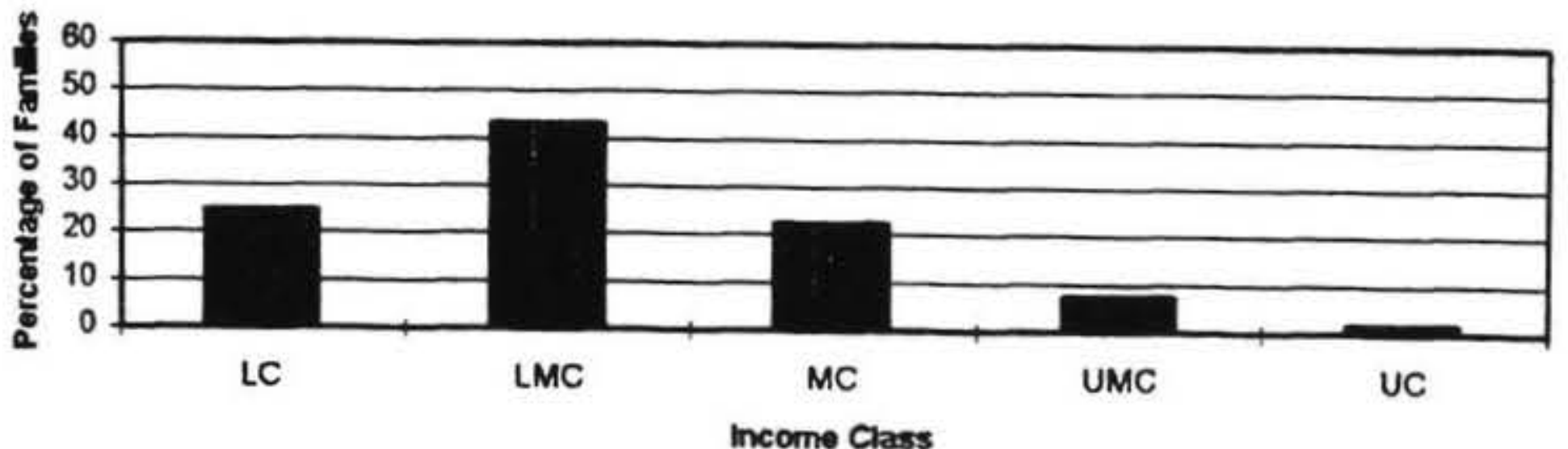

Figure 10 NM Two Parent Family Median, 1981

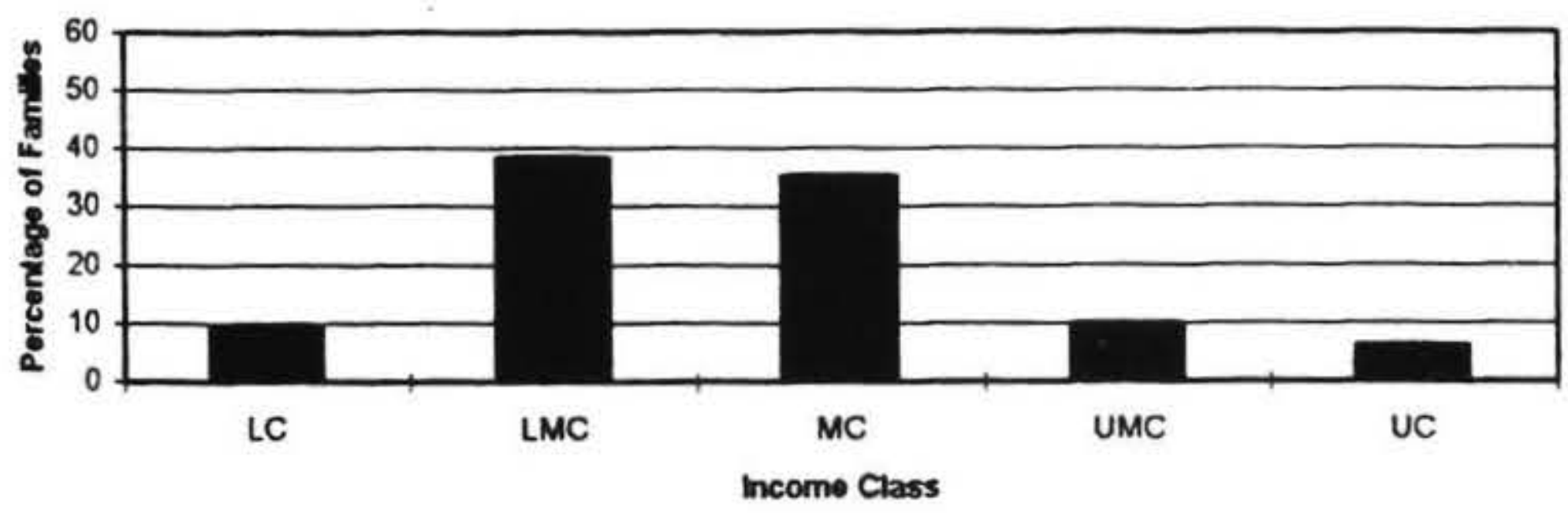


with 20 percent of Maori in the lower class. In terms of poverty, because the poverty line for the sole parent focus group is over 100 percent of the median the income classes LC, LMC and MC represent poverty, which means that less than half of Maori Male Sole parents were in poverty in 1981. By 1986 the income distribution was becoming more equal with a reduction in the extreme classes of $L C$ and UC with corresponding rises in the LMC and the MC. By 1991 the LC level had risen as had the LMC and the UMC and the UC had dropped, the 1991 distribution was more equal than the 1981 levels in terms of overall distribution but the levels of Maori Male Sole Parent poverty had increased from less than half to roughly 85 percent.

In 1981 over 70 percent of Non-Maori Male Sole Parent families were represented in the UMC and the UC, by the next census the distribution had a more equal distribution as the levels of the upper classes shifted to the LMC and the MC and yet by 1991 the reverse occurred, but not to the same extent, and the distribution became less equal just over half of the Non-Maori families above the poverty line - see Figures 16-18. The Non-Maori distribution had greater disparities between the upper and lower ends of the income distribution than Maori, especially in 1991 where NonMaori Males regained much of their upper income position that they had in 1981 whereas Maori were more evenly spread.

The income distribution for Maori Female Sole Parents in 1981 was the exact opposite of that of their male counterpart, as shown in Figures 19-21. Maori Females had much greater levels below the median and more specifically, in the LC bracket, with overall poverty about 85 percent of their total group. By 1986 their position improved slightly with a shift from the extremes of the LC and the UC, to the LMC and the $\mathrm{MC}$, this distribution remained relatively settled, but with a slight increase in the UMC and decrease in the LC in 1991. Overall, the distribution of Maori female income became more equal but poverty remained at about 85 percent, but it had dropped from the 1986 level of close to 90 percent.

Figures 22-24 show that the status of Non-Maori Female Sole Parent families in 1981 was different to Maori females as Non-Maori were not as highly over represented in the LC and had much higher levels of UMC and UC but not to the same extent as their male counterparts. By 1986 the distribution had become more equal with decreases in the LC and UMC with corresponding increases in the LMC, MC and UC. From 1986 to 1991 the LC share fell as too did the MC and the UMC and the UC grew. Poverty levels in 1981 were about 73 percent, in 198678 percent and by 1991 had dropped to about 72 percent. The actual distribution of NonMaori females had shifted from being evenly spread in the lower four classes to a distribution closer to the median and therefore more equal by 1991 .

\section{Discussion}

The income distribution of Maori families in 1981 was characterised by an over representation of the population in the lower classes and especially highly represented in the poverty bracket (Lower Class), except for the Male Sole parents who were much better off than Maori females. The Non-Maori distribution was the opposite of Maori during this period with higher levels in the upper classes (UMC and UC), but by 1986 the income distribution for both groups changed.

For Maori the change was a dramatic shift to a more equal share of the income and for Non-Maori there was a reduction in the upper income class bias with a corresponding increase of those in poverty. The National government Wage and Price Freeze which had lasted from June 1982 to October 1984 ended during this period from 1981 to 1986 and was responsible for much of the shifts in peoples incomes (Income Distriubtion Group, 1988). The end of the restrictions imposed on incomes meant that those whose had been held up by Government intervention fell while other sectors incomes rose, this accounts for the movement in family incomes described above.

The period from 1986 to 1991 saw a reversal of the trends of 1981 to 1986 with the Non-Maori income distribution become re-situated in the upper classes of the income distribution while Maori families became more unequal, with increases in the lower classes, very similar in most cases to their 1981 distribution, except for Male Sole parent families who did not differ much from Females by 1991, unlike NonMaori Male Sole parent families. The reasons for this reversal in the proportionate shares of the income distribution can be found with the corporatisation of the state sector that occurred under the Fourth Labour government, the corporatisation and restructuring resulted in large scale redundancies, especially in sectors of the economy that were employing a proportionately high percentage of Maori as opposed to Non-Maori (Pool, 1991). These redundancies contributed to much of the growth of Maori poverty as depicted in the Lower Class income brackets. This research needs therefore, to be compared alongside labour force participation rates to see the corresponding pattern.

\section{Future Research}

The position of Maori family incomes has intuitively strong links to the overall employment patterns of Maori, as income is labour market related. This paper has highlighted the patterns and trends of Maori and Non-Maori incomes during the restructuring of the $1980 \mathrm{~s}$, to fully understand and analyse these trends it is necessary to observe the relationship between trends in income equality shifts and labour force participation levels. It will also be necessary to add a further variable , that of age, into the analysis, an important factor, especially for the youthful Maori population. Analysis of the these results will give a greater depth to the understanding of the well documented restructuring that occurred during the 1980s.

\section{Notes}

1. As it is recognised that poverty changes over time and today's poverty was yesterday's standard of comfort (Royal Commission on Social Security, 1972: 104), the concept of 
Figure 11 NM Two Parent Family Median, 1986

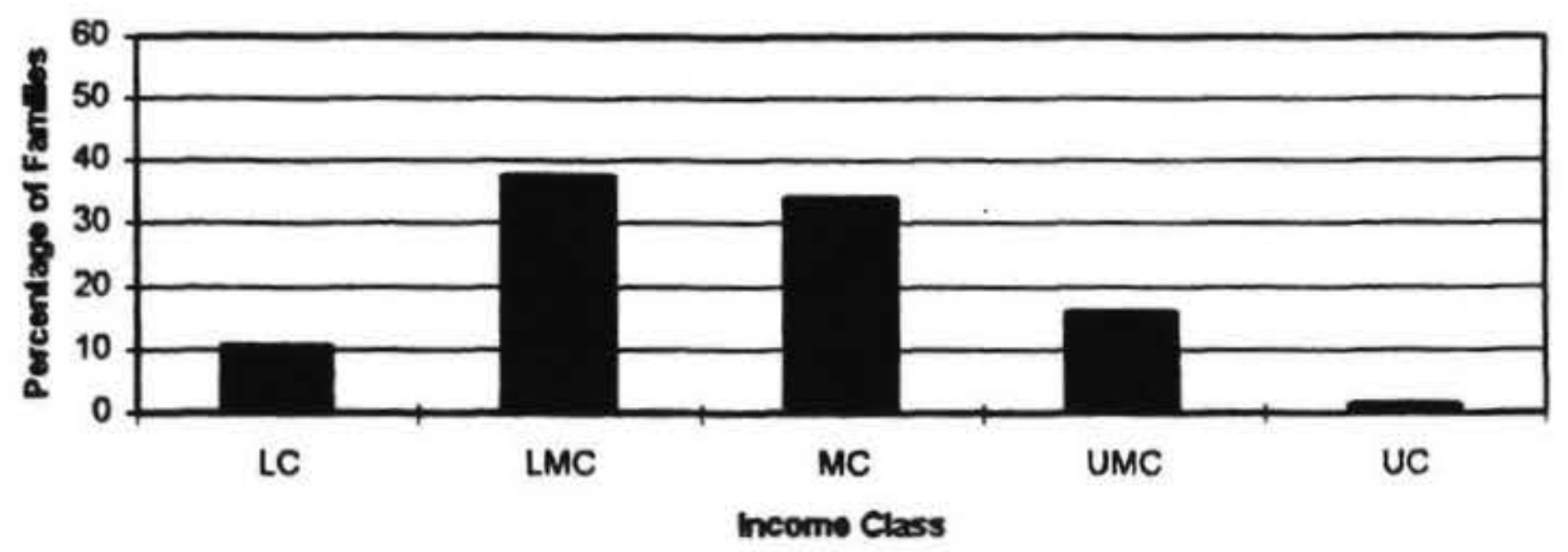

Figure 12 NM Two Parent Family Median, 1991

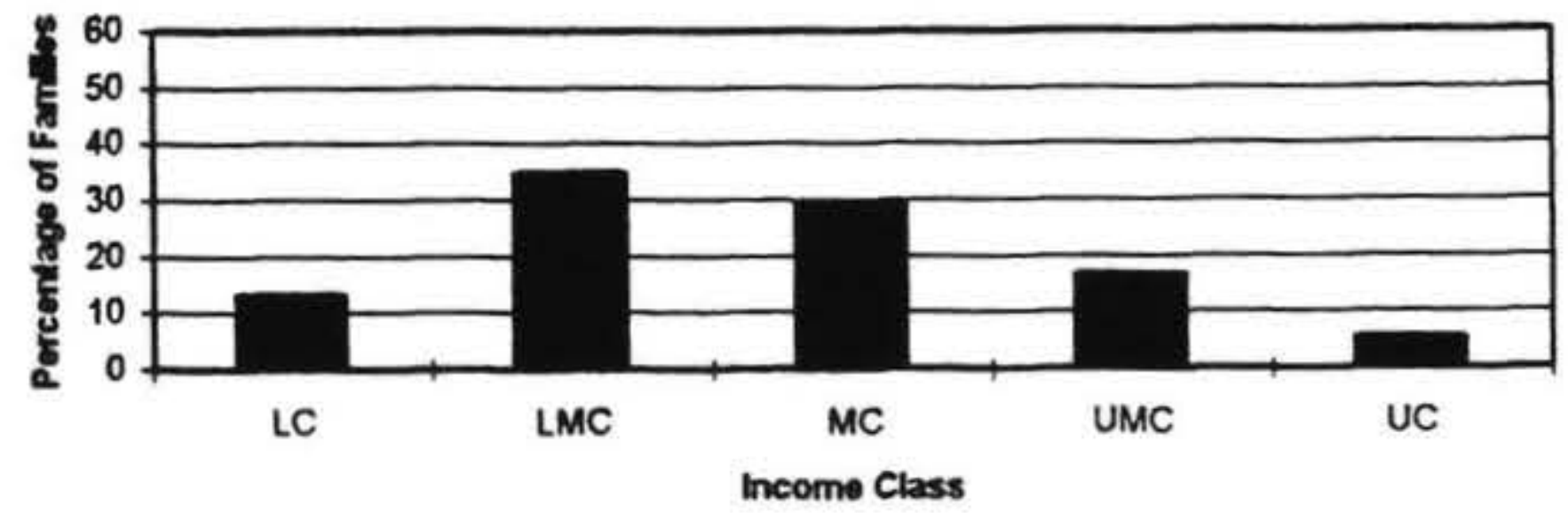

Figure 13 Maori Male Sole Parent Family Median, 1981

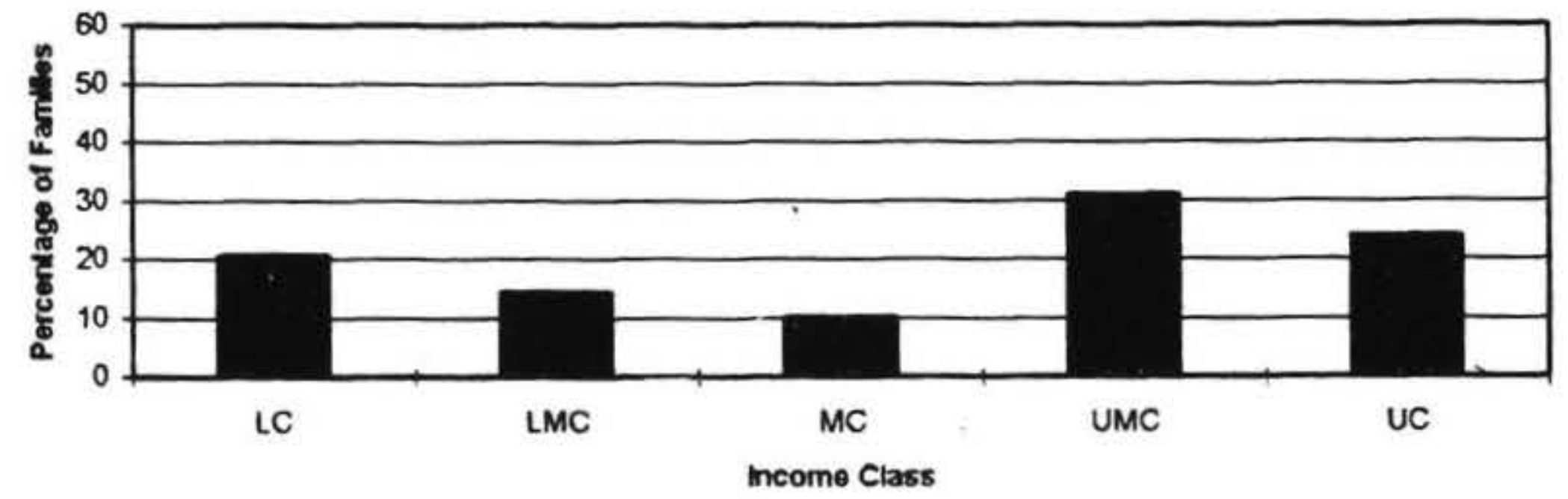

Figure 14 Maori Male Sole Parent Family Median, 1986

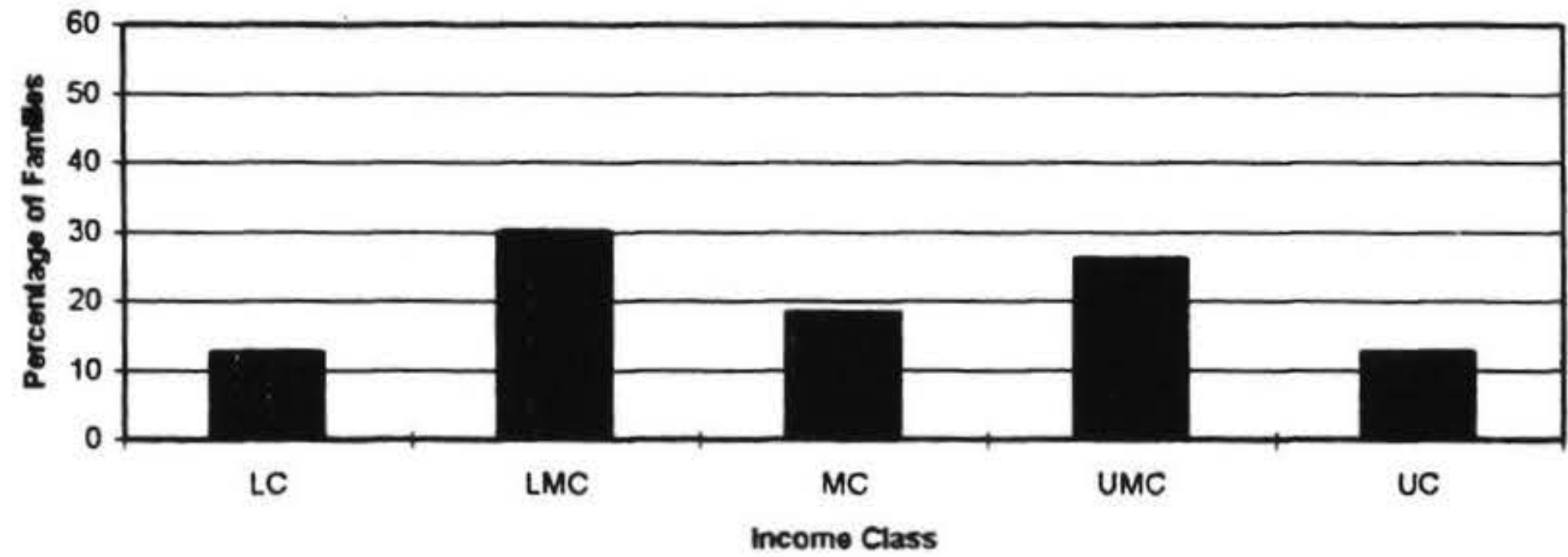

Figure 15

Maori Male Sole Parent family Median, 1991

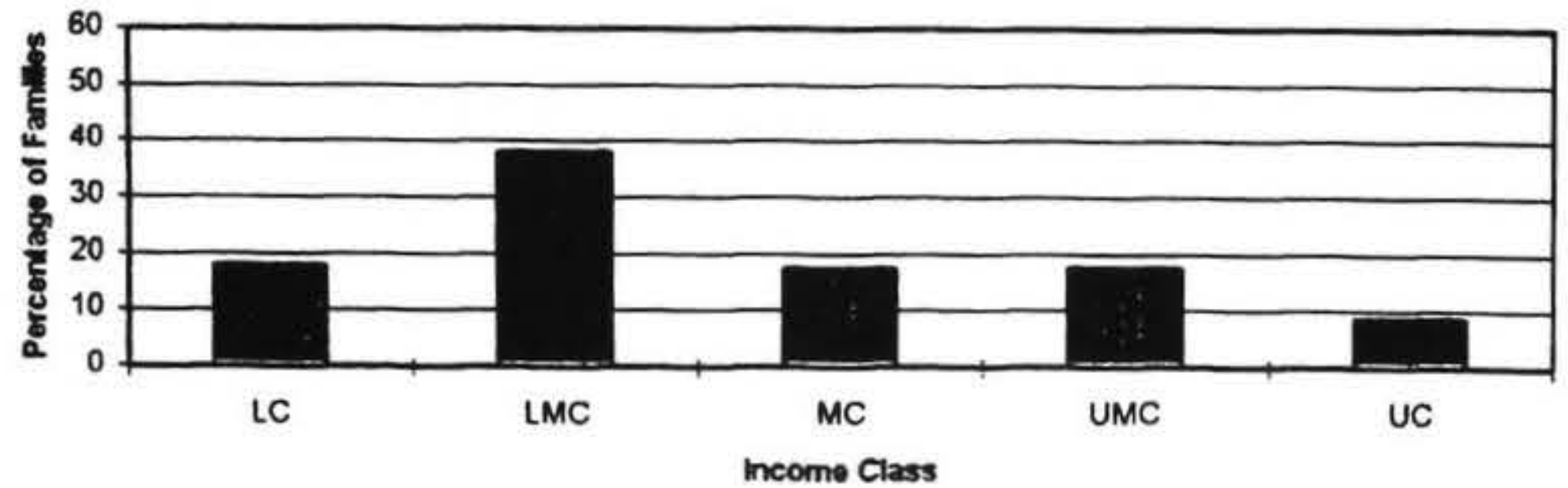




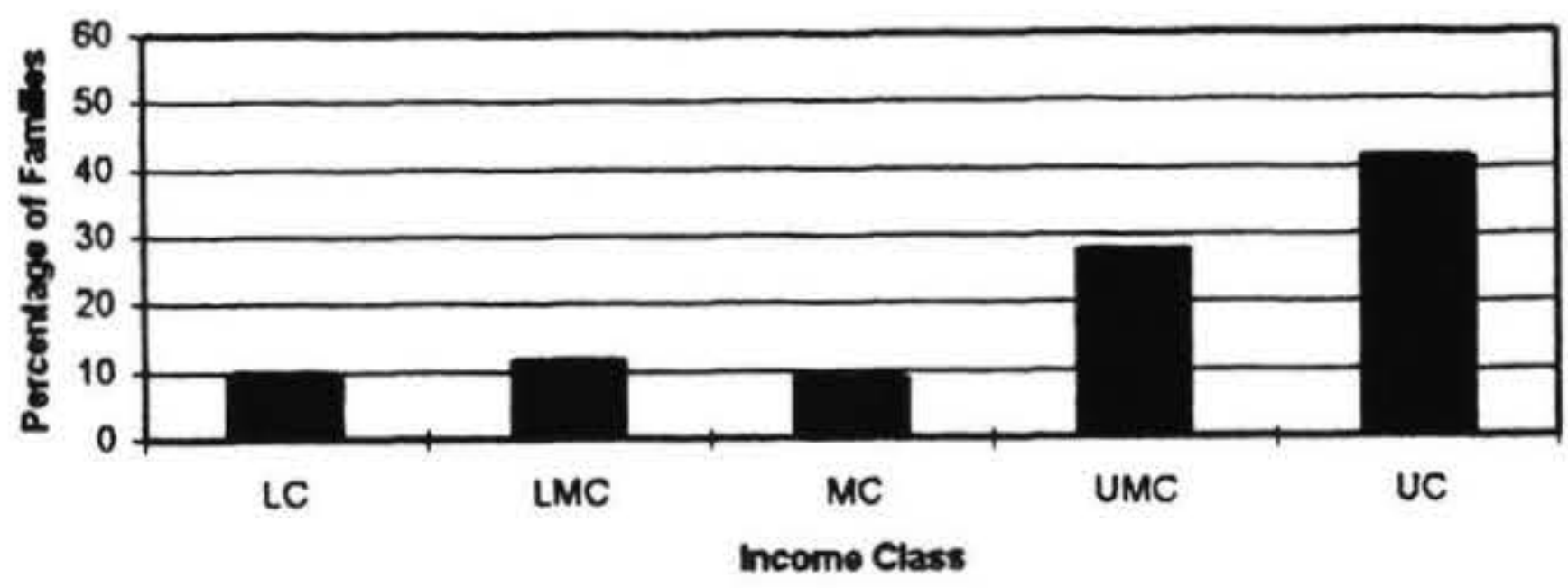

Figure 17 NM Male Sole Parent Family Median, 1986

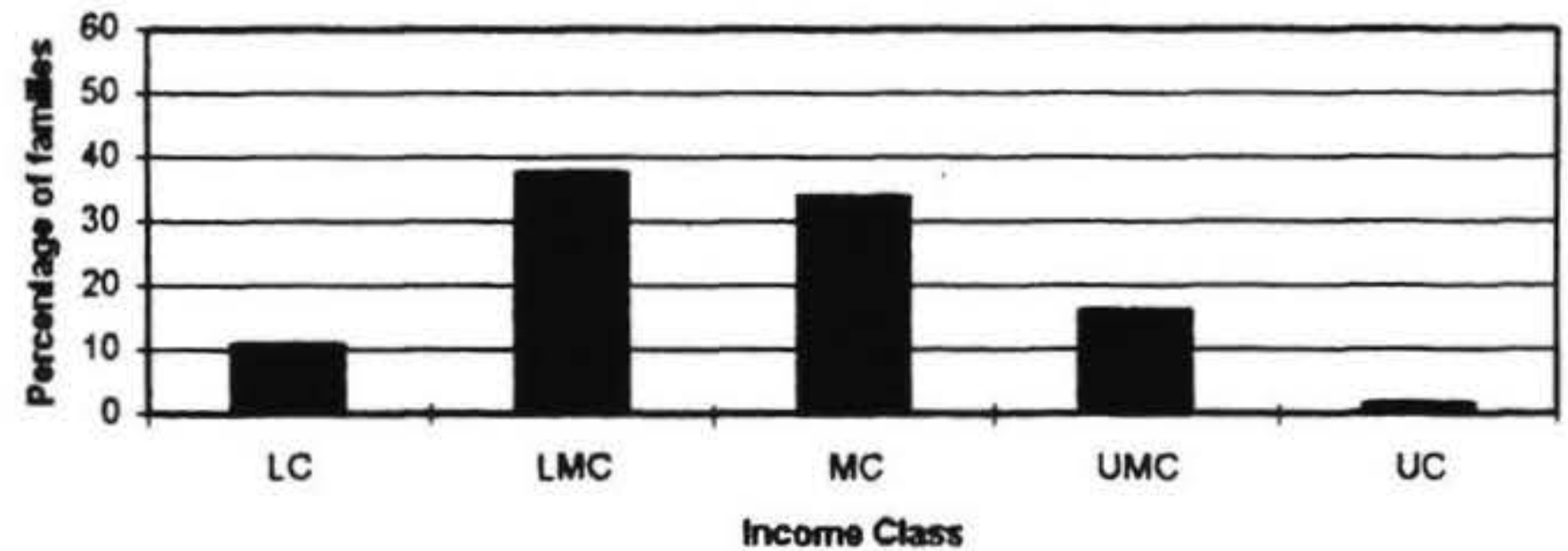

Figure 18 NM Male Sole Parent Family Median, 1991

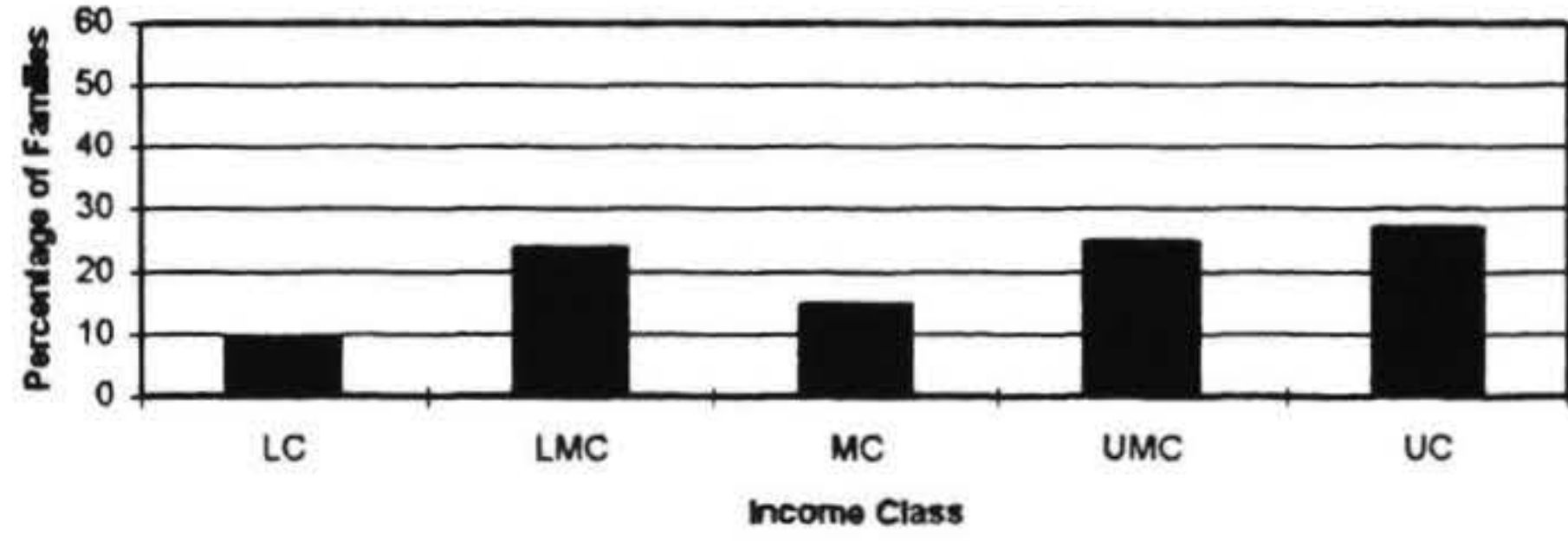

Figure 19 Maori Female Sole Parent Family Median, 1981

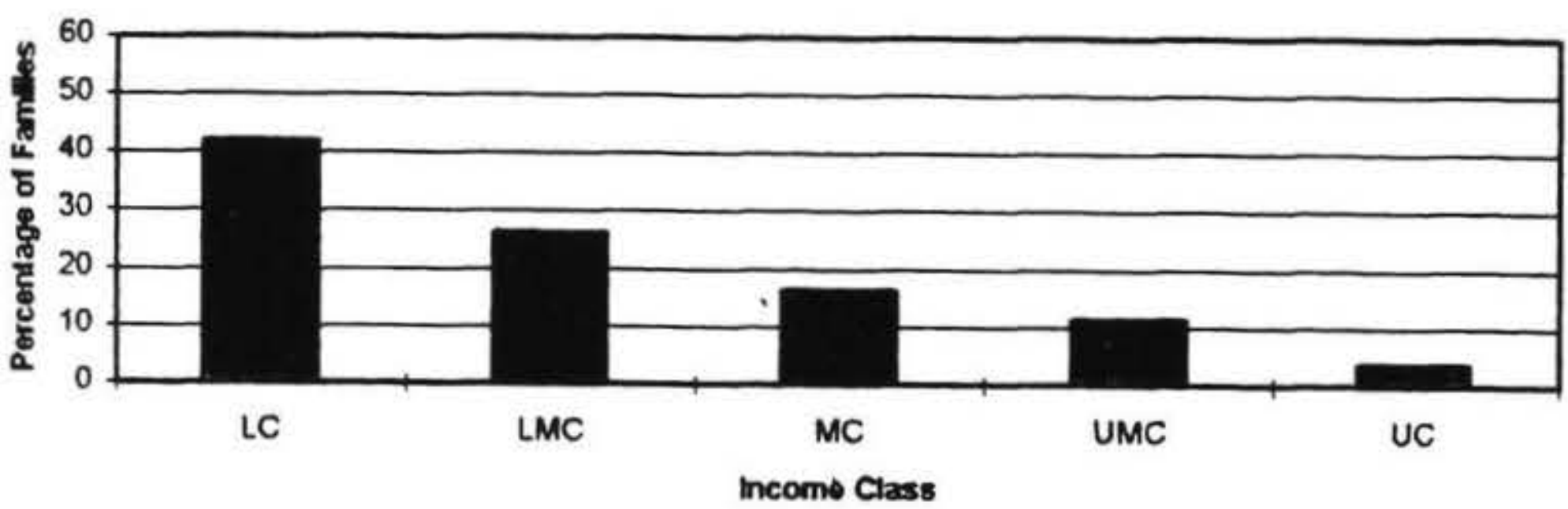

Figure 20 Maori Female Sole Parent Family Median, 1986

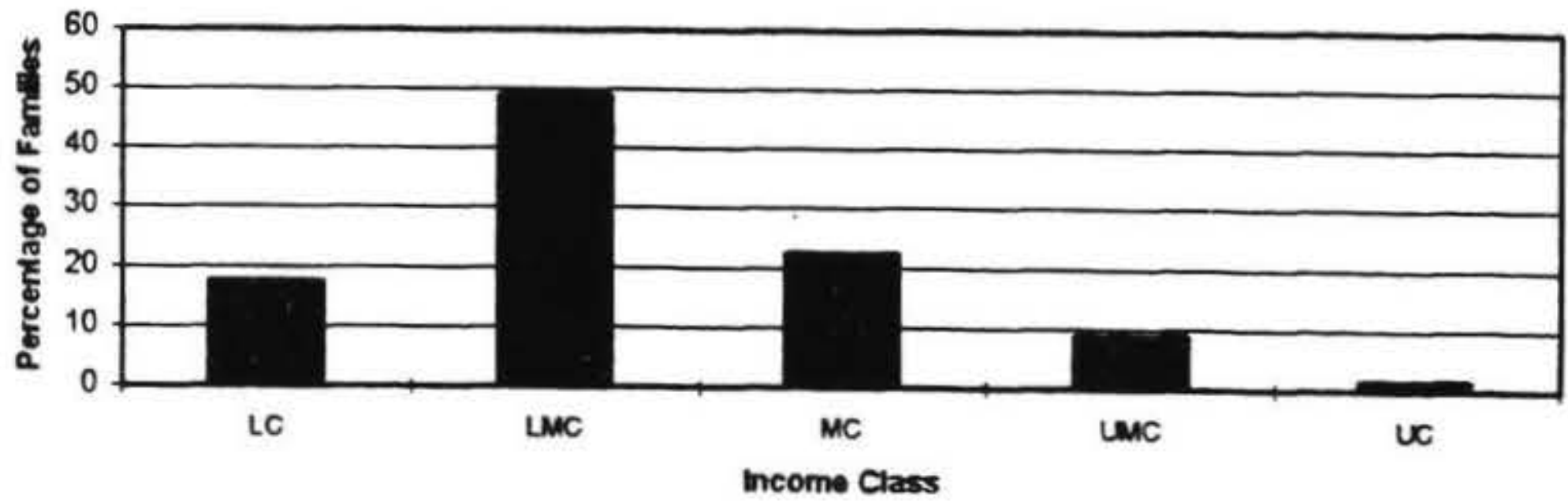


Figure 21 Maori Female Sole Parent Family Median, 1991

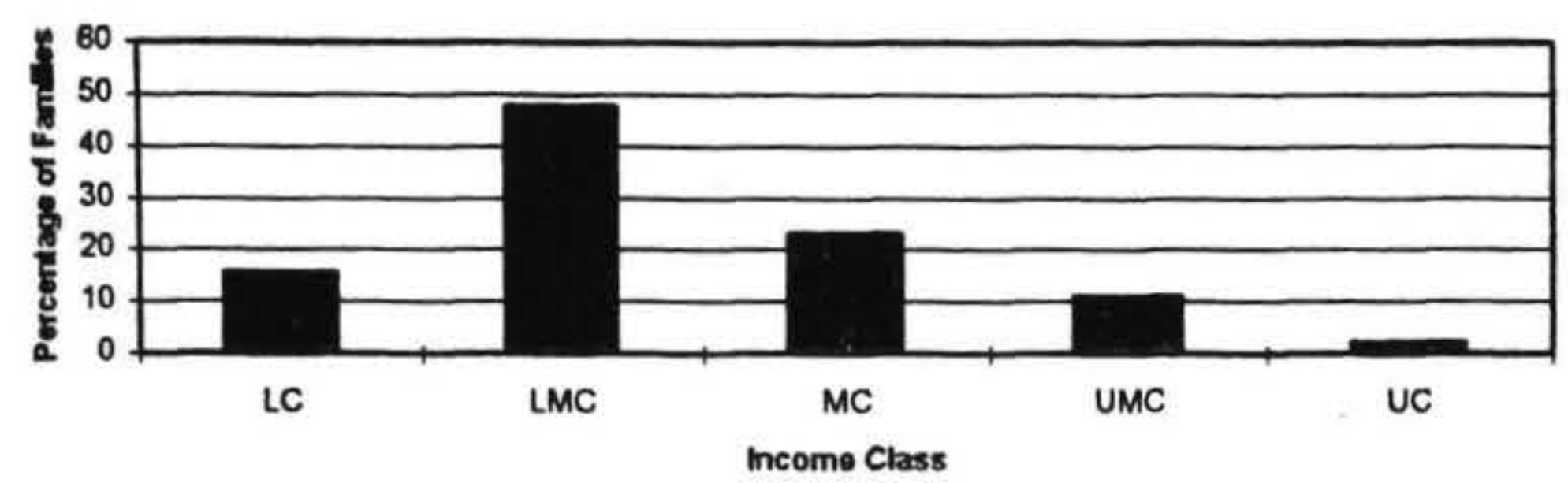

Figure 22 NM Female Sole Parent Family Median, 1981

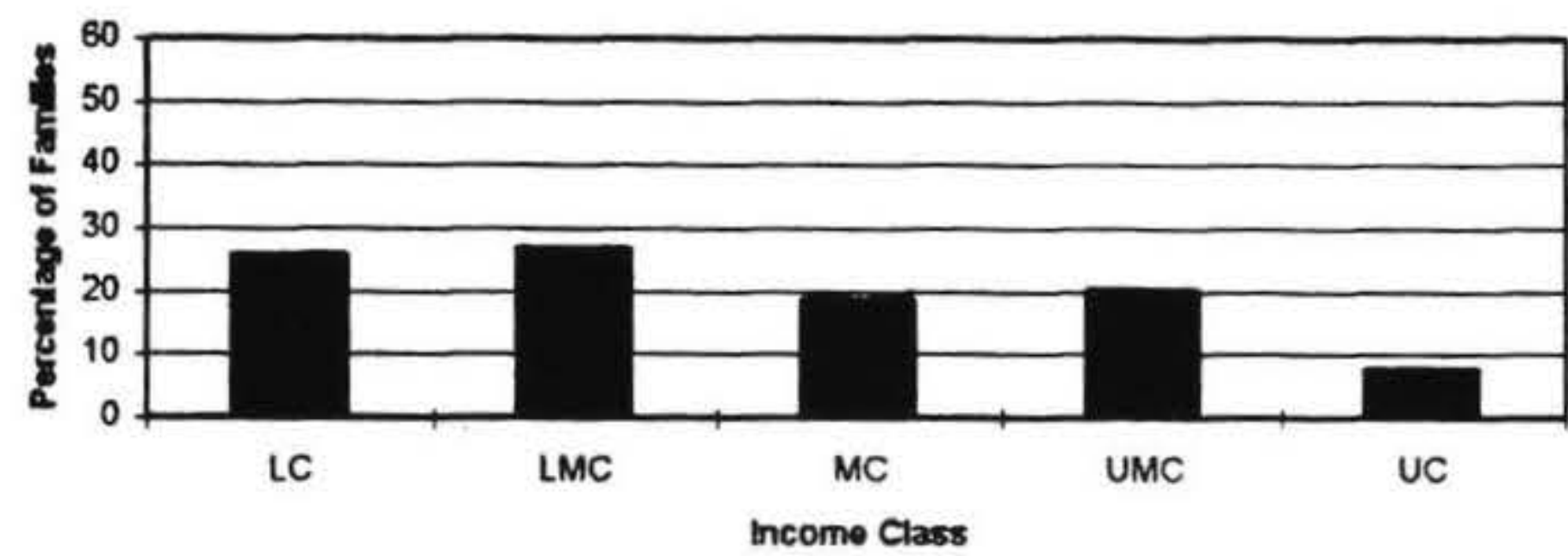

Figure 23 NM Female Sole Parent Family Median, 1986

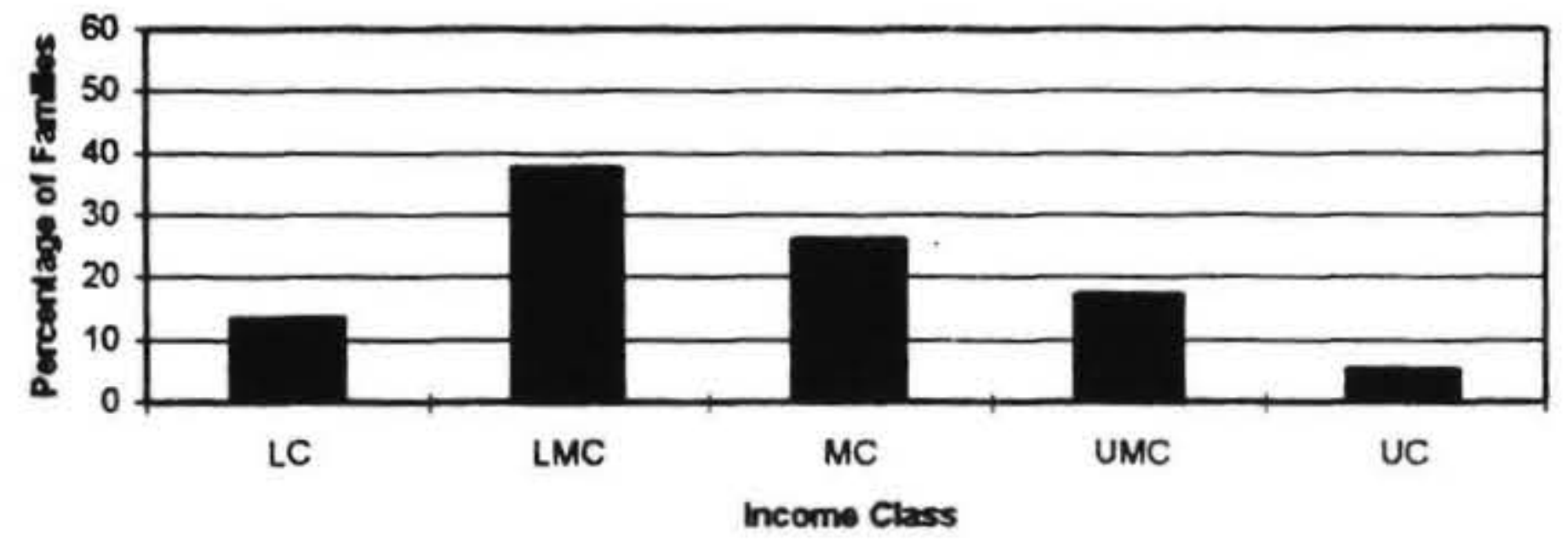

Figure 24 NM Female Sole Parent Family Median, 1991

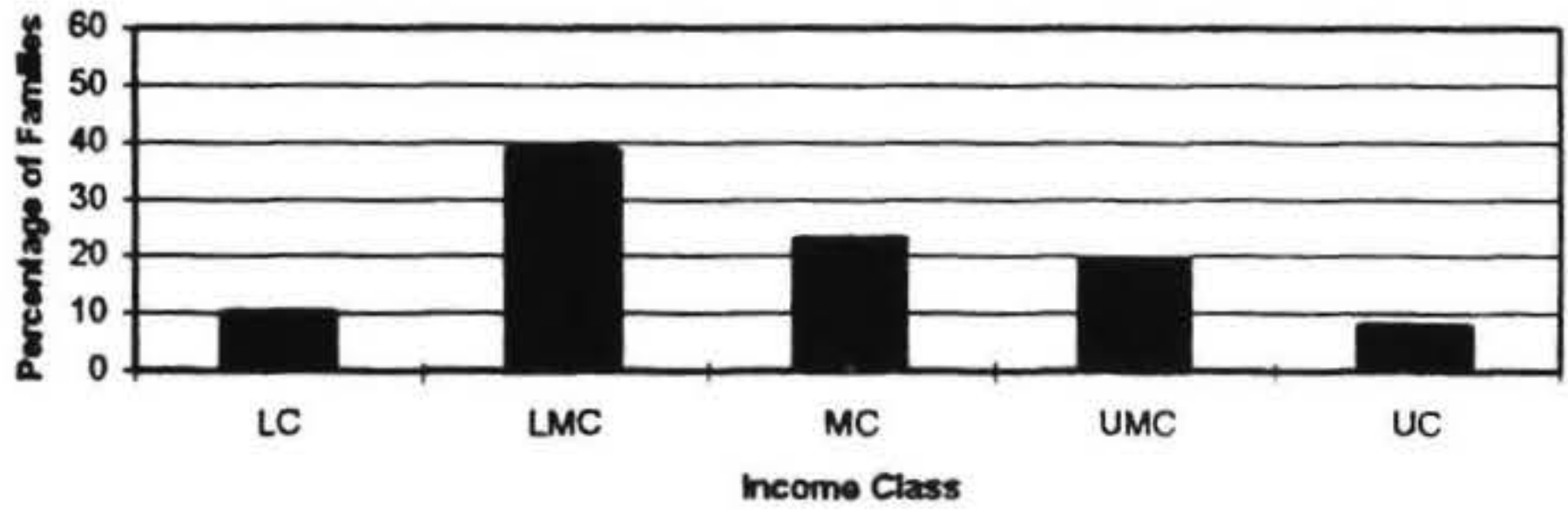


income inequality is an integral component in determining secondary poverty as it is not how much money an individual earns, but the extent to which that income allows the individual to participate in, and belong to, the community of New Zealand.

2. Richard Sawrey and Charles Waldegrave, (1993): "Minimum Adequate Income: Focus Group Study, Part I and II", Social Policy Unit, The Family Centre, Lower Hutt.

\section{References}

Blackburn, McKinley and David E. Bloom 1987 Earnings and income inequality in the United States Population and Development Review 13(4): 575-611

Bryant, George 1979 The Widening Gap: Poverty in New Zealand Cassell, Auckland

Johnstone, Kim and Ian Pool 1995 New Zealand Families: Size, Income and Labour Force Participation Discussion Paper No.10 Population Studies Centre University of Waikato Hamilton

Pool, Ian 1991 Te Iwi Maori A New Zealand Population, Past, Present Projected Auckland University Press, New Zealand

Income Distribution Group, 1988 For Richer Or Poorer, Income And Wealth In New Zealand. New Zealand Planning Council, Wellington.

Income Distribution Group, 1990 Who Gets What? The Distribution Of Income And Wealth In New Zealand. New Zealand Planning Council, Wellington.

Preston, David., 1987 Family Incomes And Government Policy, in, Conference On The Distribution of Income And Wealth In New Zealand. edited by Income Distribution Group, New Zealand Planning Council, Wellington.

Room, Graham, 1990 'New Poverty' In The European Community. MacMillan, London.

Royal Commission on Social Security 1972 Social Security in New Zealand, Report of the Royal Commission of Inquiry, Government Printer, Wellington

Sawrey, Richard and Charles Waldegrave 1993 Minimum Adequate Income: Focus Group Study, Part $I$ and II, Social Policy Unit, The Family Centre, Lower Hutt.

Stephens, Bob, Charles Waldegrave and Paul Frater 1995 Measuring Poverty In New Zealand Social Policy Journal 5: 88-109

\section{Appendix. Data Sources and Methodology}

This paper used data from a custom designed computer database prepared for the Population Studies Centre by Statistics New Zealand derived from the 1981, 1986 and 1991 censuses, with data arranged according to family type rather than household type. Family type is defined as either a couple only family, Two Parent families (with children) and, Male and Female Sole Parent families (with children). The New Zealand census definition is derived from the European idea of a nuclear family, and "therefore may not reflect the experience of New Zealand families" (Johnstone and Pool, 1995: 1)

The census definition of Ethnicity is important to consider as there was a change in definition between 1981 and 1986, to a self-identified cultural affiliation definition which has been documented, particularly for Maori (Pool, 1991). A family's ethnicity is determined using the ethnicity of the male parent or partner (except for female sole parent families). This may apply to the children but not necessarily to the partner (Johnstone and Pool, 1995: 2), especially when considering the degree of inter-marriage in New Zealand.

Ethnic identification in the database follows the hierarchical procedure for assigning multiple responses to mutually exclusive ethnic groupings, ensuring that each individual is counted only once (Johnstone and Pool, 1995: 2). The procedure is as follows (Department of Statistics, 1993: 26):

* If New Zealand Maori is one of the ethnic groups reported, the person is assigned to New Zealand Maori.

* Otherwise, if any Pacific Island group is one of the ethnic groups reported then the person is assigned to Pacific Island.

* If any group other than a European/Pakeha groups is one of the ethnic groups reported, the person is assigned to "Other".

* Otherwise, the person is assigned to European/Pakeha.

\section{Author}

Ben Amey is a Masters student at the Population Studies Centre, University of Waikato, Private Bag 3105 Hamilton, (07) 838-4138, email: bwa@Waikato.ac.nz 